\title{
Study on Relationship between Regional Cultural Heritage and Urban Park Reconstruction
}

\author{
Xuelan Yang ${ }^{1, \text { a }}$ \& Qiping Chen ${ }^{2, a}$ \\ ${ }^{1,2}$ School of civil engineering and architecture, East China Jiaotong University, Nanchang, China
}

Keywords: regional culture; inheritance; reconstruction; value dimensions

Abstract: Integration of regional culture and urban park is an important approach of landscape transformation. Landscape reconstruction of modern urban park must fully excavate and coalesce the regional culture element, in order to create new landscape with more vitality. Based on regional culture and landscape reconstruction interrelationships with uses of the value dimensions, this paper proposes the regional culture function enhanced strategies of urban park landscape reconstruction.

\section{Introduction}

The urban park landscape environment which has ecological health and cultural connotation can reflect the unique feature of city, which can shows the city style and reflects the city's image.

A successful urban park landscape can make the city feature to be transmitted, the city style to be restored $^{[1]}$. In recent years, the researchers at home and abroad make multidimensional systemic study the landscape reconstruction by the people's attitudes, behavior, and experiences ${ }^{[2]}$, the leisure space $^{[3-4]}$, ecological benefits ${ }^{[5]}$, emergency adapting ${ }^{[6]}$ and landscape pattern ${ }^{[7]}$.

At present, most scenery designs of city pay too much attention to the scenery's sense of beauty and various forms, ignoring the content's connotation and humanization. What's more, it put emphasis on the internationalization and the territory's individuation is neglected, too. For example, the project of Nanchang Poly International Garden, in order to satisfy the need of local market, adopted European classicism as its style, which is ill-adapted to the Chinese traditional architecture Pavilion of Prince Teng that surrounds it. So the two kinds of landscape look very contrary. Then as a result, Nanchang Poly International Garden couldn't reflect the special ancient cultural landscape of Nanchang city, in which it lies, as Fig.1 and Fig.2 shows.



Fig. 1 the entrance of Nanchang Poly International Garden



Fig.2 Pavilion of Prince Teng

Therefore, it is necessary to avoid getting tired of international scenery and leading to sacrificing the urban construction due to lacking long-term considerations.

\section{Relationship between regional culture and urban park reconstruction}

\section{Key factor of urban park reconstruction}

Any landscape containing the culture and history of two parts, where their embodiment of urban park, urban park is a materialistic culture, the function it has attached to cultural concepts implemented, is reflected to a certain social-economic and political ideology. In the process of landscape transformation design, as practice activities of coordination people and natural relationships, must to followed natural dialectics ${ }^{[8]}$, active mining and use of core elements of regional culture, can actively promote the regional cultural heritage, promotion of the urban 
landscape and the development of cultural industry, based on the cultural level and improve the urban landscape architecture, increasing people's memories of open space the feeling of belonging. So, regional culture is key factor of urban park reconstruction.

\section{New hermeneutic of regional cultural heritage}

The regional cultural connotation in urban park is an important symbol, which is different from the culture and landscape of other park. Regional cultural can be based on invariability cultural gene, which is into an urban park landscape though the changing path of screw type. So, urban park reconstruction is new hermeneutic of regional cultural heritage.

Urban park reconstruction reinterprets regional culture inheritance in the following ways:(1)Folk customs are inherited in the regional culture. Local customs and cultures are integrated into the urban park reconstruction, which make the urban park landscape functions behave more appealing and appeal ${ }^{[9]}$. (2)Urban park inherit the continuation genetic map of regional culture. The key connotation of regional culture is a series processes, including element recognition, theme development, bearer design, experience, feedback and design revision, which is represented in the reconstruction landscape community of urban park. The psychological demands of regional culture form new patterns of city parks by its universality and uniqueness, and the new patterns are rich in vitality and cultural ideas.

\section{Urban park reconstruction based on regional culture}

The combination of regional culture and urban park reconstruction can greatly increase the cultural connotation of scenery and inherit the beneficial culture:(1) Apply or insert regional culture to urban park reconstruction, has become the main way to improve the cities' appearance. the value of culture, economy, art and spirit that involved in regional culture can not only make the cities' development, which are more of personality, but also make its various functions more effective $^{[10]}$. (2)the designer ought to properly explore the value of the cities' regional culture when transforming the landscape. More importantly, the designer also should grasp the feature of cultural inheritance, for example, it differs from time and place. Next, it should take what people, cultural value pointed to into consideration, then take society, economy and nature, which are the mainstream of urban complex ecosystem, as basis. There are some examples that are a little highly worthwhile to be references. Such as the Nanchang Nuo culture park and Guangzhou cultural park and so on.

\section{Value dimensions of regional culture of urban park reconstruction}

The theme of the urban landscape service target is people, The environmental demand determines the development direction of city landscape planning, and the main performance of modern environmental needs to return to nature, attention to culture, enjoy the respect and affection of diversification, entertainment and personal. Therefore, the city landscape construction in addition to pay attention to its economic value, should also pay attention to the humanistic value and social value, with the regional culture as the basic point, standing in the modern people's actual environment demand angle, to explore the urban park design landscape transformation geographical and cultural heritage non-utilitarian value. Some public landscapes such as the tombstones of twelve martyrs in Chengdu cultural park, as Fig.4 shows, and the monument of the Vietnam war in Washington are also valuable to rethink.

\section{Reflective value dimensions of regional culture of urban park reconstruction}

The reflective value dimensions of regional culture mean reflecting and self-criticizing history on the base of developing and expanding tradition culture in the process of historical evolution. Penetrating the reflective ideas of regional culture into the urban park reconstruction, forming a 
good ecological and cultural development view needs us think over its spatial forming and the design feature in urban reconstruction, and inheritance of traditional folk culture, but respecting regional traditional culture does not means divorce oneself from the masses and from reality, we should inheritance and develop the traditional culture, think seriously and reference to the historical culture, let it full of vitality.

\section{Remember value dimension of regional culture of urban park reconstruction}

Honour the value dimension of regional culture in the city park transformation and Cherish the memory of thought in the regional culture has close relation with the humanism, Under the Background of various cultural landscape heritage, economics oriented by Material to spiritual change toward economics oriented by symbolic to technology. when transformer urban park, it should stand on the basis of the relationship reconstruction between man and landscape, people and people. Historical events and time spirit are established by materialization, which can generate landscape remembering process about remembering past, experience now and looking forward to future. Reconstruction of dualism is overcome for fragments man and landscape. Needing create places and attachment in leavening process, raising environment remember mood. For example Nanjing Xuanwu Park and Beijing Temple of Heaven park.

\section{Public value dimension of regional culture of urban park reconstruction}

Regional culture contain a variety of cultural system, different people and environment make different culture heritages. it also has typical locality, and is the basis of creating the city scenery's artistic images which have aesthetic feature ${ }^{[11]}$. The public value dimension of culture is mainly about the selfless dedication in spirit, besides, presentations in the scenery are educational edification, the Inclusiveness and the continuation of scenery. Consequently, in the process of making the public value dimension of culture infiltrate into the urban park reconstruction, apart from excavating the economic value, its social value also should be excavated. Basing on the regional environment, the public value orientation inherited from territory culture should be discussed.

\section{Humanistic care value dimension of regional cultural of urban park reconstruction}

Humanistic care is the care of the human spirit, is the evolution of culture and nature, man and society of mutual infiltration, mainly stressed people-centered, opposed to the various economic or spiritual condition for the development of human reason to the one-sidedness of the metaphysical human view and development view. Give full play to the role of humanistic value dimension of regional culture in the scenery, to fully tap the symbol element contains regional historical culture and public culture, fully display the characteristics of regional culture. Fusing with new ideal and spatiotemporal characteristics, through the rational long-term planning and guidance, to realize people's quality of life improved, to make full use of the regional culture of humanistic care to keep the environment protection mechanism and important role in scenery morphology.

\section{Conclusions}

Regional culture in the modern urban park designation of integration and application, what is the main project that concerned by the government and all of the relevant experts. it can max meet the people's livelihood needs and cultural demands when use the landscape function. However, the shortage of urban park design theory in China, the limitation of low cultural planning and so on, the showing of cultural landscape function transformation still need to improve. The transformation of the landscape in each current city's park still exist many problems of reality, such as unclearly features, uncertain cultural position and weaknesses in cognition of culture. On the basis of heritage and development in regional culture, it need to unify every part's lifestyle, agglomerate core values 
to make public attached themselves to national culture, arts, and beliefs firmly. So, it has practical implications to learn about the cultural function in such a background.

\section{Acknowledgment}

The authors would like to thank anonymous reviewers for their helpful comments and suggestions to improve the manuscript. This research was supported by the Engineering Research Center of Railway Environmental Vibration and Noise of Education Ministry of China (Grant No. 24341032).

\section{References}

[1] Song Hui, Wang Xiaodong: Urban planning, In Chinese,2013,(1):85-89.

[2] an Weng: Journal of Hefei technology University of (natural science Edition), 2010, 33 (6): 881-884.

[3] Gustav Kisser: Urban Forum,2008,19(4): 413-423.

[4] Dustin T. Duncan,Chirico Chinaware,Impeller White,David R. Williams.: Journal of urban health2013,90(4):618-631.

[5] Liang Haoyan, Xiao Rongbo, Liao Yuantao.: The Chinese garden, 2010,26 (9): 15-19.

[6] Ma Lin, Lu Yuqi: Areal research and development, 2010,29 (3): 73-76.

[7] Li Zhigang: Journal of East China Jiaotong University, 2007,24 (3): 60-62.

[8] Zhao Lei, Wu Wenzhi: Study on urban development, 2013,20 (9): 26-31.

[9] Deng Yan, Song Duan: Study on urban development, 2008,15 (3): 51-54.

[10] Li pingping,Qi Yuehui, Cheng Yi, Chen Lei, Su Jie, Li Xiaocui.: Art, 2011, (10): 87-89.

[11] Wang Zhong: Urban issues, 2006, (7): 98-100. 